\title{
Breast Carcinoma with Choriocarcinomatous Features
}

National Cancer Institute

\section{Source}

National Cancer Institute. Breast Carcinoma with Choriocarcinomatous Features. NCI

Thesaurus. Code C40350.

An invasive ductal breast carcinoma, not otherwise specified, characterized by increased levels of human beta-chorionic gonadotropin in the serum. Morphologic evidence of choriocarcinomatous differentiation is rare. 